See discussions, stats, and author profiles for this publication at: https://www.researchgate.net/publication/215617020

\title{
ESTUDIO FISICOQUÍMICO Y BACTERIOLÓGICO DEL RÍO MANZANARES, ESTADO SUCRE, VENEZUELA
}

Article $\cdot$ January 2008

READS

405

4 authors, including:

María Valentina Fuentes

3 Universidad de Oriente (Venezuela)

20 PUBLICATIONS 9 CITATIONS

SEE PROFILE

Luis Troccoli

Universidad de Oriente (Venezuela)

68 PUBLICATIONS 221 CITATIONS

SEE PROFILE
William Senior

Universidad Estatal de la Península de Santa...

110 PUBLICATIONS 225 CITATIONS

SEE PROFILE 
Bol. Inst. Oceanogr. Venezuela, 47 (2): 149-158 (2008); 5 Fig.

\title{
ESTUDIO FISICOQUÍMICO Y BACTERIOLÓGICO DEL RÍO MANZANARES, ESTADO SUCRE, VENEZUELA
}

\author{
María Valentina Fuentes ${ }^{1}$, William Senior ${ }^{2}$, Ivis Fermín $^{1}$, L. Troccoli ${ }^{3}$. \\ ${ }^{1}$ Escuela de Ciencias, Universidad de Oriente. Cumaná, Venezuela. \\ mariavalentinaf_1@hotmail.com, \\ ${ }^{2}$ Instituto Oceanográfico de Venezuela. Universidad de Oriente, Cumaná, Venezuela. \\ ${ }^{3}$ Escuela de Ciencias Aplicadas del Mar, Universidad de Oriente, Boca de Río, Venezuela.
}

\begin{abstract}
RESUMEN: El río Manzanares es uno de los cuerpos de agua más importantes de la región nororiental de Venezuela, sin embargo sus aguas reciben descargas de residuos agrícolas, urbanos, domésticos e industriales, algunas veces sin tratamiento previo y poco controlados por las autoridades regionales. En tal sentido, se estimó necesario conocer su estado ambiental. Para ello se establecieron 45 puntos de muestreo de agua superficial, distribuidos entre la cuenca alta, media y baja, en tres períodos diferentes: 1luvia (2003), transición (2003), sequía (2004). Los parámetros cuantificados fueron temperatura $\left(18,3-30,0^{\circ} \mathrm{C}\right)$, $\mathrm{pH}(6,04-8,88)$, oxígeno disuelto $(1,7-7,0 \mathrm{mg} .1-1)$, compuestos nitrogenados $(11-188 \mu \mathrm{mol} .1-1)$ y fosforados (nd -22 $\mu$ mol.1-1), silicatos $(8-260 \mu$ mol.1-1) y coliformes fecales $(1-2,4.107 \mathrm{NMP} / 100 \mathrm{ml})$ siguiendo los métodos estándares para el análisis de aguas naturales y de desechos (APHA- AWWA - WPCF). Todos los parámetros cuantificados mostraron diferencias en las tres cuencas y en las tres épocas. La cuenca más afectada resultó ser la baja. Los nitratos y nitritos fueron las especies inorgánicas predominantes, relacionándose con alta presencia de coliformes fecales, abundante materia orgánica descompuesta y las temperaturas más cálidas. Los resultados demuestran la baja calidad ambiental del río Manzanares, cuyas aguas podrían catalogarse como no adecuadas para el contacto humano.
\end{abstract}

Palabras clave: Elementos nutritivos, agua, río Manzanares, contaminación

ABSTRACT: The Manzanares River is one of the most important bodies of water in northeastern Venezuela. However, a vast influx of industrial and domestic sewage from farm and urban dwellings enters the river without much control by the pertinent authorities. To ascertain the environmental quality of the river 45 sampling sites were set throughout the area comprising the high, middle, and low-lying areas of the river basin during three different periods, namely, rainy season (2003), transitional period (2003), and dry season (2004). The parameters monitored and measured following APHA-AWWA-WPCF standards were: temperature $\left(18.3-30.0^{\circ} \mathrm{C}\right), \mathrm{pH}(6.04-8.88)$, dissolved oxygen $\left(1.7-7.0 \mathrm{mg} . \mathrm{L}^{-1} \mathrm{k}\right)$, nitrogen $(11-188$ $\mu$ mol. $\left.1^{-1}\right)$ and phosphorus compounds (nondetectable $-22 \mu$ mol. $\left.1^{-1}\right)$, silicates $\left(8-260 \mu \mathrm{mol}^{1} \mathrm{1}^{-1}\right)$, and fecal coliforms $(1-2.4$ - $10^{7} \mathrm{MPN} / 100 \mathrm{~mL}$ ). All parameters yielded differences in the three watersheds and the three seasons. The low-lying area resulted most affected. Nitrates and nitrites were the prevailing inorganic matter, in consonance with a high presence of fecal coliforms, profuse decomposed organic matter, and warmer temperatures. Results attest to the poor environmental quality of the Manzanares River, the waters of which being unsuited for human exposure.

Key words: Nourishing elements, water, Manzanares River, pollution

\section{INTRODUCCIÓN}

La presencia de ciertas especies químicas en los ríos está determinada por la calidad de las rocas de su cuenca, el tipo de suelo lixiviado por las aguas de lluvia y la cantidad de materia orgánica terrestre acarreada. Estas sustancias aportan los elementos nutritivos (N, P, Si) que sostienen la productividad primaria de las regiones costeras (MARTínez et al. 2001) y junto a las condiciones climáticas determinan las características fisicoquímicas de sus aguas. Sin embargo, Martínez \& Senior (2001) han señalado que los procesos físicos, químicos, biológicos e hidrodinámicos naturales de los ríos pueden ser 
modificados por el vertido de residuos. Además, estos vertidos pueden cambiar notablemente la calidad del agua y producir daños irreversibles a la biota (BENNER, 2004).

Aunque el río Manzanares es uno de los cuerpos de agua más importantes de la región Nororiental de Venezuela, ya que abastece de agua potable a toda la zona, no se escapa de esta realidad. En sus márgenes están ubicados la ciudad de Cumaná y otros centros poblados, cuyos residuos son vertidos, en la mayoría de los casos, sin tratamiento previo y sin control de las autoridades competentes (MARTínez et al. 2001). Así por ejemplo, se evidencian en sus márgenes estructuras habitacionales en condiciones deplorables de salubridad, desechos líquidos descargados desde una procesadora de pescado ubicada en su desembocadura, desechos sólidos y líquidos generados en el mercado municipal, residuos de una estación de servicios, de un astillero naval y de una planta de hielo. Esta última utiliza amoníaco durante el proceso de refrigeración (MÁRQUEZ et al. 2002b).

Martínez et al. (2001) han informado sobre la disminución del $\mathrm{pH}$ y el oxígeno disuelto y sobre el incremento de las concentraciones de los compuestos nitrogenados y fosforados, en ciertos sectores. GUTIÉRREZ \& Rivero (2000) señalaron índices alarmantes de contaminación patógena, en su principal tributario, el río Guasdua, y en la entrada y salida de la laguna de oxidación del central azucarero de Cumanacoa. MÁrQuez et al. (2002a) han encontrado concentraciones elevadas de metales pesados en sus aguas y sedimentos; Martínez \& SENIOR (2001) hallaron relación entre la cantidad de metales, el material suspendido y el gasto del río, y evidencias de metales pesados antropogénicos en el material en suspensión, asociados con carbonatos y oxihidróxidos de manganeso. Todos estos factores alteran la calidad de las aguas del río y las condiciones ambientales de las aguas costeras de la ciudad de Cumaná (MARTínez, 2005).

En tal sentido, se ha considerado relevante estudiar algunos parámetros fisicoquímicos y bacteriológicos desde la cuenca alta hasta la cuenca baja del río Manzanares, y en distintas temporadas. Así se dispondría de valores actualizados para continuar su evaluación periódica e incentivar su recuperación.

\section{MATERIALES Y MÉTODOS}

El río Manzanares se encuentra entre las coordenadas $63^{\circ} 45^{\prime} 30^{\prime \prime}$ y $63^{\circ} 19^{\prime} 20^{\prime \prime}$ de longitud Oeste y entre $10^{\circ} 05^{\prime}$ $30^{\prime \prime}$ y $10^{\circ} 29^{\prime} 20^{\prime \prime}$ latitud Norte (Fig. 1). Esta zona presenta un régimen pluviométrico de dos períodos fundamentales: seco (diciembre - junio) y lluvioso (julio - noviembre). $\mathrm{Su}$ vertiente está situada a $2.300 \mathrm{~m}$ sobre el nivel del mar, en el macizo Turimiquire, y desemboca en el Golfo de Cariaco. Su hoya hidrográfica tiene una extensión de $1.652 \mathrm{~km}^{2} \mathrm{y}$ descarga anualmente $771 \times 10^{6} \mathrm{~m}^{3}$ de agua al mar, repartidas entre el aliviadero y su desembocadura. Sus aguas se desplazan por un cauce de $81 \mathrm{~km}$, con una pendiente mínima de $15 \%$ y un gasto medio de $1,23 \mathrm{~m}^{3}$. $\mathrm{s}^{-1}$ (SENIOR 1994; Martínez 2005). Recibe la descarga de nueve ríos, trece riachuelos y quebradas por su margen derecha, mientras que por la izquierda llegan catorce ríos principales y seis secundarios (MÁRQUEZ et al. 2002a, 2002b). De estos afluentes, el Guasdua aporta una gran cantidad de contaminantes domésticos, procedentes de Cumanacoa y otros poblados, y desechos industriales del central azucarero Cumanacoa (SENIOR 1994; AlvarAdo 2000). En sus márgenes, según un informe CTI-MARNR del año 1999, están asentados aproximadamente 51.977 habitantes, de los cuales $51,9 \%$ corresponden a población rural y $48,1 \%$ a población urbana, sin embargo se estima que estas cantidades han incrementando.

Se tomaron muestras de agua superficial en 45 estaciones de muestreo distribuidas de la siguiente manera: doce en la cuenca alta $(1-12)$, quince en la cuenca media $(13-27)$ y dieciocho en la cuenca baja $(28-45)$, en tres temporadas distintas: octubre 2003 (época lluviosa), diciembre 2003 (época de transición) y febrero 2004 (época de sequía).

Los parámetros cuantificados mediante la metodología normalizada por la Asociación Americana de Salud Pública para Análisis de Aguas Potables y Residuales (APHAAWWA-WPCF 1992) fueron: nitritos y nitratos $\left(\mathrm{NO}_{2}+\right.$ $\mathrm{NO}_{3}$ ), nitrógeno orgánico disuelto (NOD), nitrógeno total (NT), amonio $\left(\mathrm{NH}_{4}\right)$, nitrógeno inorgánico disuelto (NID), nitritos $\left(\mathrm{NO}_{2}\right)$, oxígeno disuelto $\left(\mathrm{O}_{2}\right)$, fosfato $\left(\mathrm{PO}_{4}\right)$, fósforo total (PT), silicatos $\left(\mathrm{SiO}_{4}\right)$ y coliformes fecales. La temperatura y el $\mathrm{pH}$ fueron medidos in situ con un termómetro de mercurio $\left( \pm 0,1^{\circ} \mathrm{C}\right)$ y un peachímetro Bantex LCGS5 ( \pm 0.01$)$, equipado con una sonda ATC.

Los resultados se representan como diagramas de caja y bigote, herramientas estadísticas poderosas que muestran la mediana, la media, el intervalo, la forma de la distribución de los datos y sirven como una gráfica de 
Estudio fisicoquímico y bacteriológico del río Manzanares
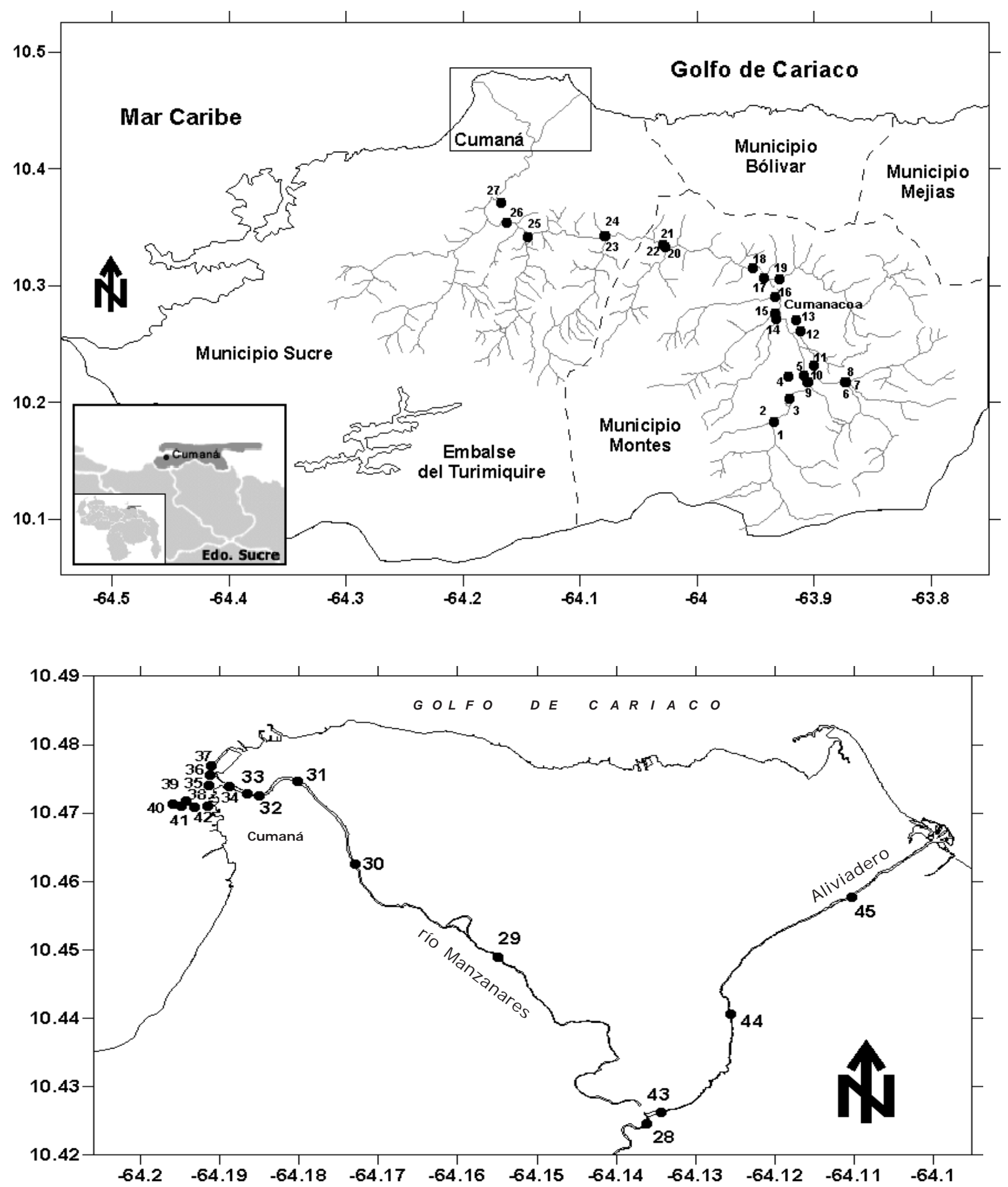

Fig. 1. Río Manzanares. Ubicación geográfica. Estaciones de muestreo. 
ANOVA no paramétrica (BOYER et al. 2000). RESULTADOS YDISCUSIÓN

\section{Temperatura}

Los diagramas de caja y bigote (Fig. 2a) revelan diferencias significativas entre los resultados de temperatura en las tres épocas $(\mathrm{PF}<0,05)$. En la época lluviosa, este parámetro estuvo ente 21,1 y 29,1

${ }^{\circ} \mathrm{C}, \bar{X}$ (media) $=26,2{ }^{\circ} \mathrm{C}, \mathrm{DER}$ (desviación estándar relativa) $=8 \%$, temperaturas más altas que las sucedidas en la época de transición, las cuales variaron entre 20,4 y $27,0^{\circ} \mathrm{C}(\bar{X}=$ $24,3^{\circ} \mathrm{C}, \mathrm{DER}=6 \%$ ). A su vez, esta temporada mostró aguas más cálidas que la época de sequía, entre 18,3 y $26,9^{\circ} \mathrm{C}$ $\left(\bar{X}=23,1^{\circ} \mathrm{C}, \mathrm{DER}=10 \%\right)$. En cuanto a las medianas de la temperatura del agua por cuencas (Fig. 2b), las temperaturas más frías se observaron en la cuenca alta $\left(18,3-28,3^{\circ} \mathrm{C}, \bar{X}=22,8^{\circ} \mathrm{C}, \mathrm{DER}=12 \%\right)$, temperaturas ligeramente superiores se presentaron en la cuenca media $\left(22,4-29,1^{\circ} \mathrm{C}, \bar{X}=24,8^{\circ} \mathrm{C}, \mathrm{DER}=7 \%\right)$, y en la cuenca baja se alcanzaron las temperaturas más cálidas $\left(24,2-30^{\circ} \mathrm{C}\right.$, $\bar{X}=26,2^{\circ} \mathrm{C}, \mathrm{DER}=6 \%$ ). Estos resultados concuerdan con los informados en otras investigaciones (SENIOR \& Godoy 1990; Godoy 1991; León et al. 1997; Martínez et al. 2001).

Los resultados expresan que la temperatura del agua está controlada por las condiciones climáticas: altitud de las cuencas respecto al nivel del mar, fluctuación periódica de la intensidad solar, temperatura del aire, velocidad del viento, dirección del viento y las precipitaciones que modifican el caudal. Respecto a esto, SeNIOR et al. (1991) concluyeron que la temperatura del río está dominada por los ciclos estacionales y el caudal del río, como consecuencia de las precipitaciones ocurridas en la cuenca alta.

\section{$p H$}

De acuerdo a la época, los valores de $\mathrm{pH}$ variaron como sigue: época lluviosa $(7,53-8,53, \bar{X}=8,11, \mathrm{DER}=3 \%)$, época de transición $(7,21-8,8, \bar{X}=8,3, \mathrm{DER}=4 \%)$, época de sequía $(6,04-8,88, \bar{X}=8,06, \mathrm{DER}=17 \%)$. El pH por época del año (Fig. 2c) no mostró diferencias significativas, a un nivel de confianza del $95 \%$, corroborado por el análisis de varianza de Kruskall-Wallis $(\mathrm{PF}<0,05)$.

El mínimo valor de $\mathrm{pH}(6,04)$ se encontró cerca del mercado municipal de Cumaná (cuenca baja), y el máximo $(8,88)$ en La Fuente (cuenca alta). Particularmente, los resultados por cuenca fueron: alta $(7,70-8,80 ; \bar{X}=7,70$; $\operatorname{DER}=3 \%)$, media $(7,21-8,88 ; \bar{X}=8,17 ;$ DER $=5 \%) y$ baja $(6,04-8,74 ; \bar{X}=7,94 ; \mathrm{DER}=7 \%)$. Las gráficas de caja y bigote $(\mathrm{PF}<0,05)$ y la prueba de intervalo múltiple indicaron diferencias significativas $(95 \%)$ del $\mathrm{pH}$ del agua entre cuencas (Fig. 2d), especialmente entre las cuencas alta y baja. El valor mínimo de $\mathrm{pH}$ fue similar a 6,80, valor señalado por SENIOR et al. (1999), en el mismo sitio. Los resultados inducen a pensar que las diferencias de $\mathrm{pH}$ encontradas en el ecosistema pueden ser provocadas por la descomposición de la materia orgánica desechada en el río, la resuspensión de sedimentos, los cambios en la fuerza iónica al mezclarse agua dulce y salada, los cuales pueden provocar el descenso del pH. Esta situación es más marcada en la desembocadura (cuenca baja). Respuesta similar encontraron MARTínez et al. (2001) en la desembocadura y la pluma del Manzanares.

\section{Oxígeno disuelto}

El oxígeno disuelto en la época de lluvia (Fig. 2e) mostró valores entre 2,0 y 6,2 mg. $\mathrm{l}^{-1}\left(\bar{X}=5,2 \mathrm{mg} \cdot \mathrm{l}^{-1}, \mathrm{DER}=18 \%\right)$, en la época de transición entre 4,2 y 6,3 mg.1-1 $(X=5,2$ $\mathrm{mg} \cdot \mathrm{l}^{-1}, \mathrm{DER}=9 \%$ ) y en la época de sequía entre 1,6 y 7,0 $\operatorname{mg} \cdot 1^{-1}\left(\bar{X}=5,7 \mathrm{mg} \cdot \mathrm{l}^{-1}, \mathrm{DER}=17 \%\right)$. La comparación de estos resultados por el análisis de varianza demuestra la uniformidad del oxígeno en el tiempo, ya que no existen diferencias significativas $(\mathrm{PF}>0,05)$.

En general, el oxígeno disuelto (Fig. 2f) estuvo entre 1,7, Quebrada Sequía (cuenca alta) y 7,0 mg. $1^{-1}$, en Cumanacoa (cuenca media). En particular, las variaciones por cuenca fueron: alta $\left(1,7-6,5 \mathrm{mg} .1^{-1}, \bar{X}=5,3 \mathrm{mg} . \mathrm{l}^{-1}\right.$, DER $=23 \%)$, media $\left(3,6-7,0 \mathrm{mg} \cdot .^{-1}, \bar{X}=5,5 \mathrm{mg} .1^{-1}, \mathrm{DER}=\right.$ 11\%), baja (3,3 - 6,2 mg. $\mathrm{l}^{-1}, \bar{X}=5,0 \mathrm{mg} \cdot \mathrm{l}^{-1}$, DER $\left.=11 \%\right)$. Estas concentraciones de oxígeno disuelto en la cuenca baja mostraron diferencias significativas con las concentraciones de oxígeno en las cuencas alta y media, en las cuencas alta y media fueron similares pero mayores que en la cuenca baja. Cabe destacar la baja concentración de oxígeno disuelto en las aguas del río Guasdua (4,2 
mg..$^{1-1}$ ), sitio donde SENIOR et al. (1999) encontraron 5,6 mg. $1^{-1}$, debido al aumento de la carga contaminante.

La disminución del oxígeno disuelto puede atribuirse a descensos del $\mathrm{pH}$, al consumo de este elemento durante la oxidación de la materia orgánica vertida y a la menor solubilidad del oxígeno en las aguas salobres. A pesar de la carga orgánica vertida en su cuenca y transportada por el caudal del río, sus aguas superficiales mantienen altas concentraciones de oxígeno disuelto.

\section{Compuestos nitrogenados}

Las concentraciones de nitrógeno total (NT), por cuenca (Fig. 3a), fluctuaron de la siguiente manera: cuenca alta entre 22 y $104 \mu \mathrm{mol}^{-\mathrm{l}^{-1}}\left(\bar{X}=62 \mu \mathrm{mol} . \mathrm{l}^{-1}\right.$, DER $\left.=39 \%\right)$, cuenca media entre 11 y $152 \mu \mathrm{mol}^{1} \mathrm{l}^{-1}\left(\bar{X}=57 \mu \mathrm{mol.} \mathrm{l}^{-1}\right.$, $\mathrm{DER}=53 \%$ ) y cuenca baja entre 12 y $188 \mu \mathrm{mol}^{-1} \mathrm{l}^{-1}(\bar{X}=59$ $\mu \mathrm{mol} / \mathrm{l}, \mathrm{DER}=63 \%)$. Sin embargo, durante la época de lluvia el NT varió entre 14 y $167 \mu \mathrm{mol} . \mathrm{l}^{-1}\left(\bar{X}=65 \mu \mathrm{mol.1} \mathrm{l}^{-1}\right.$, $\mathrm{DER}=44 \%$ ), en la época de transición entre 11 y $188 \mu$ mol.1 ${ }^{1}\left(\bar{X}=71 \mu \mathrm{mol}^{1} \mathrm{l}^{-1}, \mathrm{DER}=43 \%\right)$ y en la época de sequía entre 12 y $152 \mu$ mol. $\mathrm{l}^{-1}\left(\bar{X}=41 \mu \mathrm{mol} . \mathrm{l}^{-1}, \mathrm{DER}=61 \%\right)$. La localidad con menor concentración fue río Cedeño (cuenca media) y las mayores concentraciones se registraron en el río Guasdua (cuenca media), en las inmediaciones del mercado municipal de Cumaná y en la desembocadura del río Manzanares (cuenca baja). Estos resultados coinciden con los obtenidos por SENIOR et al. (1999), quienes encontraron la concentración menor de compuestos nitrogenados en río Cedeño $\left(27 \mu \mathrm{mol}^{1 \mathrm{l}^{-1}}\right)$ y el mayor (58 $\mu$ mol..$\left.^{-1}\right)$ en el río Guasdua.

Aunque las estaciones del año y el gasto del río influencian la distribución de los compuestos nitrogenados, la presencia de desechos orgánicos e inorgánicos determinan en gran medida las concentraciones de nitrógeno total. Godoy (1991) y Senior et al. (1999) reportaron altas concentraciones de nitrógeno total en los últimos tres kilómetros del río en el mar y los relacionaron con el período de mayor caudal del río. MARTinez et al. (2001) indicaron que los residuos vertidos desde viviendas, sin servicios sanitarios, ubicadas en las márgenes del río, los restos de pescados expendidos en la boca del río, los efluentes de algunas industrias, entre otros, son los responsables de la gran cantidad de nitrógeno presente
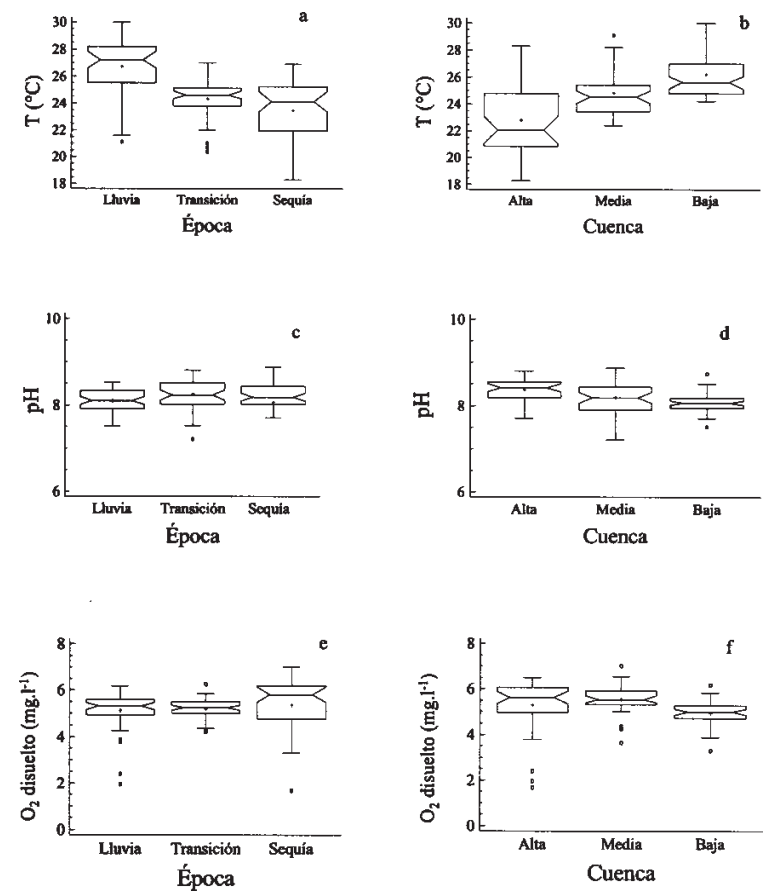

Fig. 2. Variación de la temperatura, pH, oxígeno disuelto en las aguas superficiales del río Manzanares.

en el agua.

En cuanto a las concentraciones de nitrógeno inorgánico disuelto (NID) por cuenca (Fig. 3a) se presentaron así: cuenca alta entre 4 y $43 \mu$ mol. $^{-1}(\bar{X}=21$ $\mu$ mol..$^{-1}$, DER $=56 \%$ ), cuenca media entre 3 y $80 \mu \mathrm{mol}^{-1}{ }^{-1}$ $\left(\bar{X}=21 \mu\right.$ mol. $\left..^{-1}, \mathrm{DER}=75 \%\right)$ y cuenca baja entre 1 y 36 $\mu$ mol..$^{-1}\left(\bar{X}=16 \mu\right.$ mol. $\left..^{-1}, \mathrm{DER}=56 \%\right)$, mientras que por épocas los intervalos fueron: lluvia $\left(6-32 \mu \mathrm{mol}^{-1} \mathrm{I}^{-1}, \bar{X}=\right.$ $\left.16,7 \mu \mathrm{mol} .1^{-1}, \mathrm{DER}=41 \%\right)$, transición $\left(4-54 \mu \mathrm{mol}^{1} \mathrm{l}^{-1}, \bar{X}=\right.$ $24 \mu$ mol. $\left.1^{-1}, \mathrm{DER}=54 \%\right)$ y sequía $\left(3-80 \mu \mathrm{mol}^{-1} \mathrm{l}^{-1}, \bar{X}=17\right.$ $\mu$ mol. $.^{-1}, \mathrm{DER}=76 \%$ ). El valor más elevado se encontró en el río Guasdua, valores aproximadamente la mitad de los encontrados en el río, anteriormente citado, se registraron en La Fragua, río Yoraco, pertenecientes a la cuenca alta y en Quebrada seca, Pie de Cuesta y Quebrada Orinoco, localidades de la cuenca media. El análisis comparativo de muestras múltiples (Fig. 3a) exhibe las diferencias significativas $(\mathrm{PF}<0,05)$ entre los contenidos de las formas 
nitrogenadas, por cuenca y por época, y revela que gran parte del nitrógeno total arrastrado por el río se presenta en forma orgánica. Este mismo hallazgo ha sido señalado por SENIOR et al. (1999).

El nitrógeno orgánico disuelto (NOD) mostró los siguientes intervalos de concentraciones, respecto a las cuencas: alta $\left(18-64 \mu \mathrm{mol} .1^{-1}, \bar{X}=41 \mu \mathrm{mol} .1^{-1}, \mathrm{DER}=\right.$ 37\%), media (no detectado, nd $-85 \mu \mathrm{mol}^{1} \mathrm{l}^{-1}, \bar{X}=37 \mu \mathrm{mol} . \mathrm{l}^{-}$ ${ }^{1}, \mathrm{DER}=58 \%$ ) y baja (nd $-165 \mu \mathrm{mol}^{-1} \mathrm{1}^{-1}, \bar{X}=44 \mu \mathrm{mol} . \mathrm{l}^{-1}$, DER $=80 \%$ ). Respecto a las épocas del año (Fig. 3b), los intervalos fueron: lluvia $\left(4-143 \mu \mathrm{mol}^{-1} \mathrm{l}^{-1}, \bar{X}=48 \mu \mathrm{mol} . \mathrm{l}^{-1}\right.$, DER $=52 \%$ ), transición (nd $-165 \mu \mathrm{mol}^{-1} \mathrm{I}^{-1}, \bar{X}=48 \mu \mathrm{mol} . \mathrm{l}^{-}$ ${ }^{1}, \mathrm{DER}=50 \%$ ) y sequía (nd $-100 \mu \mathrm{mol}^{-1} \mathrm{l}^{-1}, \bar{X}=25 \mu \mathrm{mol} . \mathrm{l}^{-}$ ${ }^{1}, \mathrm{DER}=79 \%$ ). Los sitios con mayor abundancia de NOD se ubicaron en la ciudad de Cumaná (alrededores del mercado municipal, puente Guzmán Blanco, desembocadura del río).

El NID, fracción de nitrógeno más pobre en las cuencas del río Manzanares, se detectó fundamentalmente bajo las formas de nitratos $\left(\mathrm{NO}_{3}\right)$ y nitritos $\left(\mathrm{NO}_{2}\right)$, con predominio del nitrato, ya que el nitrito es prácticamente constante en toda el área estudiada (nd - $10 \mu$ mol. $^{-1}, \bar{X}=1 \mu \mathrm{mol}^{-1}{ }^{-1}$, $\mathrm{DER}=2 \%$ ). La sumatoria de las concentraciones de estas dos especies mostraron en la cuenca alta concentraciones entre 4 y $41 \mu \mathrm{mol} .1^{-1}\left(X=19 \mu \mathrm{mol} .1^{-1}, \mathrm{DER}=61 \%\right.$ ), en la cuenca media entre 3 y $40 \mu \mathrm{mol}^{-1} \mathrm{l}^{-1}\left(\bar{X}=15 \mu \mathrm{mol} . \mathrm{l}^{-1}\right.$, DER $=$ $69 \%$ ) y en la baja entre 1 y $28 \mu \mathrm{mol}^{-1} \mathrm{l}^{-1}\left(\bar{X}=11 \mu \mathrm{mol} . \mathrm{l}^{-1}\right.$, $\mathrm{DER}=70 \%$ ). Estos mismos parámetros por época (Fig. $3 \mathrm{~d}$ ) exhibieron contenidos que fluctuaron entre 4 y $23 \mu \mathrm{mol}^{-1} \mathrm{l}^{-1}$ $\left(\bar{X}=11 \mu \mathrm{mol} \cdot \mathrm{l}^{-1}, \mathrm{DER}=49 \%\right.$ ) en la época de lluvia, entre 1 y $41 \mu \mathrm{mol} . \mathrm{l}^{-1}\left(\bar{X}=20 \mu \mathrm{mol} . \mathrm{l}^{-1}, \mathrm{DER}=63 \%\right)$ en la época de transición y entre 3 y $40 \mu \mathrm{mol} .1^{-1},\left(\bar{X}=14 \mu \mathrm{mol}^{-1}{ }^{-1}\right.$, DER $=$ $60 \%$ ) en la sequía. El máximo valor se registró en el río Guasdua.

El análisis de varianza del intervalo múltiple mostró diferencias significativas $(\mathrm{PF}<0,05)$, respecto a nitrito $\mathrm{y}$ nitrato en las cuencas (Fig. 3c). Su abundancia fue decreciendo en el siguiente orden: alta $>$ media $>$ baja.
Cabe resaltar que los contenidos de nitrito no fueron estadísticamente diferentes en las cuencas. Sin embargo, al estudiar el comportamiento de nitritos y nitratos por época, las medianas de la época lluviosa y sequía fueron estadísticamente diferentes respecto a la mediana de la época de transición ( $\mathrm{PF}<0,05)$, cuando los valores se elevaron considerablemente (Fig. 3d). Estos resultados indican que la presencia de materia orgánica en estado avanzado de descomposición es el factor predominante, seguido del nitrato drenado desde el suelo procedente de la actividad agrícola, la cual es mayor en la cuenca alta.

Al realizar el análisis de varianza por comparación de muestras múltiples (Fig. 3e), las concentraciones de $\mathrm{NH}_{4}$ fueron significativamente diferentes a la suma de las concentraciones de $\mathrm{NO}_{2}$ y $\mathrm{NO}_{3}(\mathrm{PF}<0,05)$, corroborando el hecho que la especie de NID predominante es el $\mathrm{NO}_{3}$.

El elemento nutritivo $\mathrm{NH}_{4}$ mostró valores entre no detectado y $5 \mu \mathrm{mol}^{-1} \mathrm{l}^{-1}\left(\bar{X}=2 \mu \mathrm{mol} . \mathrm{l}^{-1}\right.$, DER $\left.=60 \%\right)$ en la cuenca alta, entre no detectado y $40 \mu^{\mathrm{mol}} \mathrm{I}^{-1}(\bar{X}=5$ $\mu \mathrm{mol} \cdot 1^{-1}, \mathrm{DER}=130 \%$ ) en la cuenca media y entre no detectado y $20 \mu \mathrm{mol} . \mathrm{I}^{-1}\left(\bar{X}=5 \mu \mathrm{mol} .^{-1}\right.$, DER $\left.=67 \%\right)$ en la cuenca baja, mientras que en la época de lluvia entre no detectado y $18 \mu \mathrm{mol} . \mathrm{I}^{-1}\left(\bar{X}=6 \mu \mathrm{mol} . \mathrm{l}^{-1}\right.$, DER $\left.=75 \%\right)$, en la época de transición entre 1 y $18 \mu \mathrm{mol}^{-1} \mathrm{I}^{-1}\left(\bar{X}=4 \mu \mathrm{mol} . \mathrm{l}^{-1}\right.$, $\mathrm{DER}=70 \%$ ) y en la época de sequía entre no detectado $\mathrm{y}$ $40 \mu \operatorname{mol}^{1} \mathrm{l}^{-1}\left(\bar{X}=4 \mu \mathrm{mol} .1^{-1}, \mathrm{DER}=184 \%\right)$. Su máxima concentración se detectó en el río Guasdua (cuenca media) y aproximadamente la mitad de la concentración de amonio en el agua del río Guasdua se presentó en el agua del río Caribe (cuenca media) y en varios sectores de la ciudad de Cumaná (lonja pesquera, puente Guzmán Blanco y desembocadura del río). El análisis de intervalos múltiples (Fig. 3e) detectó diferencias significativas $(\mathrm{PF}<0,05)$ en la abundancia de amonio entre la cuenca alta y la media y entre la alta y la baja (alta $<$ media $<$ baja), no así respecto a las épocas del año (PF $>0,05)$. Probablemente, las altas concentraciones, en las cuencas media y baja, se deban a la liberación de amonio durante la oxidación de la abundante materia orgánica exógena.

\section{Compuestos fosforados}

De manera similar a los compuestos nitrogenados, las concentraciones de fósforo total (PT), fósforo orgánico 
disuelto (POD) y fosfato $\left(\mathrm{PO}_{4}\right)$ fueron diferentes $(\mathrm{PF}<$ 0,05 ), como lo indica el análisis de muestras múltiples (Fig. $4 a)$. Además revela que gran parte del fósforo arrastrado por el río es fósforo orgánico disuelto (POD).

En general, las concentraciones de PT variaron desde no detectado, en el río Cedeño (cuenca media) hasta 22 $\mu$ mol. $1^{-1}$ en el parque Guaiquerí (Cumaná, cuenca baja), $\bar{X}$ $=4 \mu \mathrm{mol}_{1} \mathrm{l}^{-1}$, DER $=95 \%$. Las concentraciones de POD fluctuaron entre no detectado, en río Arenas (cuenca media) y $22 \mu$ mol..$^{-1}$ (mercado municipal, Cumaná), $\bar{X}=3 \mu$ mol.1 ${ }^{1}, \mathrm{DER}=122 \%$; y las de fosfato $\left(\mathrm{PO}_{4}\right)$ desde no detectado, en La Fuente (cuenca alta), hasta 11,2 $\mu$ mol..$^{-1}$ (puente Gonzalo de Ocampo, Cumaná), $\bar{X}=1 \mu$ mol. ${ }^{-1}$, DER $=$ $108 \%$. Otras áreas con valores elevados fueron el río Aricagua (cuenca alta) y el aliviadero El Peñón (cuenca baja). Estos resultados reflejan el comportamiento paralelo de fósforo total y fosfatos. Este mismo comportamiento fue observado por SENIOR et al. (1999).

Cabe resaltar las diferencias significativas existentes entre las tres cuencas $(\mathrm{PF}<0,05)$ en relación al fosfato (Fig. 4b), el cual se manifiesta más abundante en la cuenca alta que en la media y en ésta a su vez más abundante que en la baja. Sus concentraciones no son diferentes si las comparamos por épocas del año ( $\mathrm{PF}>0,05)$, situación similar a la observada para el amonio, nitratos y nitritos.

Las concentraciones de POD en la cuenca alta variaron entre no detectado y $9 \mu \mathrm{mol}^{1} \mathrm{l}^{-1}\left(\bar{X}^{-}=2 \mu \mathrm{mol}^{1} \mathrm{l}^{-1}\right.$, DER $=$ $94 \%$ ), en la cuenca media entre no detectado y $8 \mu \mathrm{mol}^{-1}{ }^{-1}$ $\left(\bar{X}^{-}=3 \mu \mathrm{mol} .1^{-1}, \mathrm{DER}=108 \%\right)$ y en la baja entre no detectado y $22 \mu \mathrm{mol} .1^{-1}\left(\bar{X}^{-}=3 \mu \mathrm{mol} . \mathrm{l}^{-1}, \mathrm{DER}=144 \%\right)$, mientras que las concentraciones por época estuvieron entre no detectado y $22 \mu$ mol. $1^{-1}\left(\bar{X}^{-}=5 \mu\right.$ mol. $1^{-1}$, DER $\left.=87 \%\right)$ en la época de lluvia, entre no detectado y $5 \mu \mathrm{mol}^{-1} \mathrm{l}^{-1}\left(\bar{X}^{-}=2\right.$ $\mu$ mol. $.^{-1}, \mathrm{DER}=60 \%$ ) en la época de transición y entre no detectado y $9 \mu \mathrm{mol} .1^{-1}\left(\bar{X}^{-}=1 \mu \mathrm{mol} .1^{-1}\right.$, DER $\left.=159 \%\right)$ en la época de sequía.

El análisis de varianza no mostró diferencias significativas entre las concentraciones de POD (Fig. 4b) presentes en las tres cuencas ( $\mathrm{PF}>0,05)$, sin embargo la mediana de la época de lluvia fue distinta, estadísticamente, a la mediana de las concentraciones en las épocas de
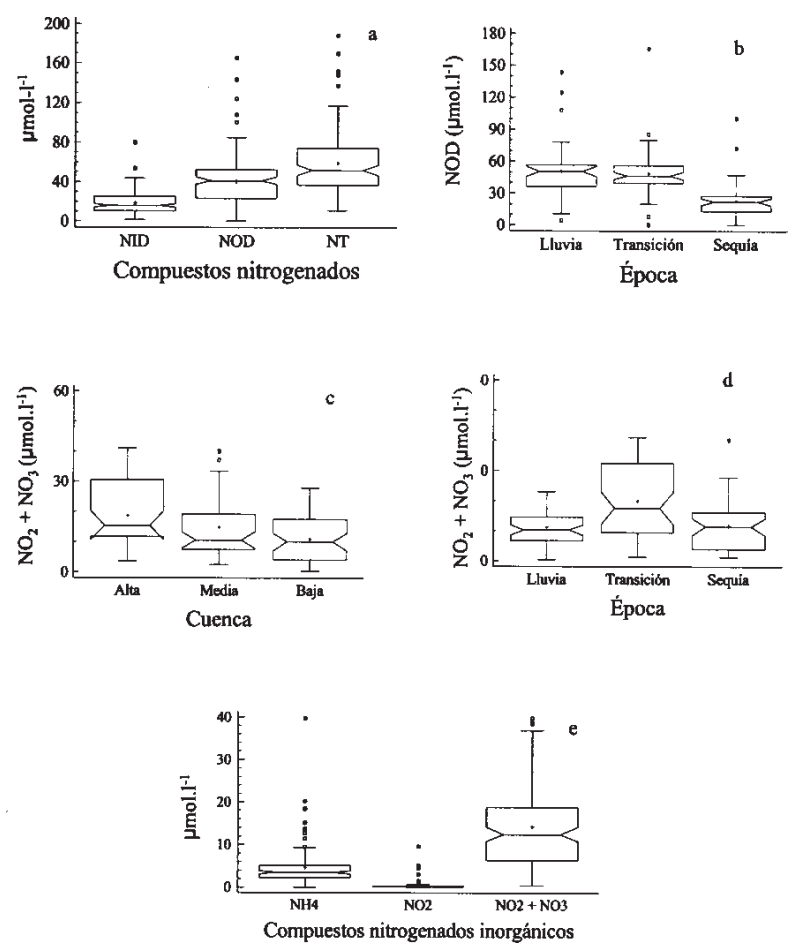

Fig. 3. Variación de los compuestos nitrogenados en las aguas superficiales del río Manzanares.

transición y sequía, es decir en la época de lluvia la concentración de POD fue mucho mayor que en las épocas de transición y sequía.

Las concentraciones de fósforo son indicativas de las actividades agrícolas que se desarrollan durante todo el año. El uso de plaguicidas y fertilizantes contribuyen al aumento progresivo de este nutriente, que al presentarse en forma soluble en los suelos puede ser drenado por las aguas de lluvia hacia el río. Además las personas radicadas en las márgenes de los ríos usan detergentes de polifosfatos, que por efecto de la hidrólisis y de la actividad bacteriana incrementa el fósforo en el medio. Otro factor importante de contaminación por fósforo son las heces fecales de los residentes de la zona y la descomposición de tejidos de organismos. Además, el incremento del fósforo total y la disminución del $\mathrm{pH}$ revelan los aportes de aguas servidas en el río. En cuanto a esto, MARTínez et al. (2001) informan que los principales aportes de fosfatos son los efluentes domésticos e industriales, los cuales contienen altas concentraciones de detergentes 
fosforados.

\section{Silicatos}

Las variaciones de las concentraciones en las cuencas fueron: alta $\left(34-247 \mu \mathrm{mol} .1^{-1}, \bar{X}=141 \mu\right.$ mol. ${ }^{-1}$, DER $=$ 24\%), media (24-186 $\mu$ mol. $1^{-1}, \bar{X}=139 \mu$ mol. $^{-1}$, DER $=$ $17 \%$ ) y baja ( $8-260 \mu$ mol. $^{-1}, \bar{X}=99 \mu$ mol. $\left.^{-1}, \mathrm{DER}=55 \%\right)$. Las concentraciones de la cuenca media fueron significativamente diferentes (Fig. 4c) a las concentraciones de las cuencas alta y media $(\mathrm{PF}<0,05)$. Sin embargo, las concentraciones de silicatos en la cuenca alta y en la cuenca media no mostraron diferencias estadísticas significativas. En la cuenca baja, se encontraron los contenidos más bajos, probablemente porque los silicatos son removidos por cambios en la fuerza iónica y $\mathrm{pH}$, produciendo la floculación de sustancias disueltas y la deposición de arcillas. Respecto a esto, Martínez \& SENior (2001) han señalado que el descenso de la concentración de silicatos en la cuenca baja es una consecuencia de la mezcla entre las aguas dulces y marinas.

Respecto a las concentraciones por época fueron: lluvia entre 98 y $225 \mu$ mol. $^{1-1}\left(\bar{X}=145 \mu \mathrm{moll}^{-1}{ }^{-1}\right.$, DER $\left.=19 \%\right)$, transición entre 7 y $247 \mu \mathrm{mol} . \mathrm{l}^{-1}\left(\bar{X}=114 \mu \mathrm{mol}^{1 .^{-1}}\right.$, DER $=$ $41 \%$ ) y sequía entre 78 y $171 \mu \mathrm{mol} .1^{-1}(\bar{X}=129 \mu \mathrm{mol} / 1$, $\mathrm{DER}=16 \%$ ). No se encontraron diferencias significativas entre los contenidos de silicatos $(\mathrm{PF}>0,05)$ en las diferentes épocas estudiadas (Fig. 4d), es decir la concentración de silicatos no se asocia con el gasto del río. Situación similar encontró Godoy (1991) en la cuenca baja, concentraciones de silicatos dependientes de procesos físicos, como la dilución, que suceden durante la mezcla de agua del río y mar, y variaciones temporales no relacionadas con el gasto del río.

\section{Coliformes fecales}

$\mathrm{El}$ análisis de varianza de una cola de la presencia de coliformes a lo largo de la cuenca del río (Fig. 4e) indicó diferencias significativas entre cuencas. Esta abundancia se manifiesta ligeramente superior en la cuenca media, con valores comprendidos entre $4.10^{2}$ y $24.10^{6} \mathrm{NMP} / 100 \mathrm{ml}(\bar{X}$ $=4.10^{4} \mathrm{NMP} / 100 \mathrm{ml}, \mathrm{DER}=33 \%$ ). El valor máximo de la cuenca media se registró en el río Guasdua. Los resultados en la cuenca alta variaron entre 1 y $2.10^{6} \mathrm{NMP} / 100 \mathrm{ml}(\bar{X}$ $=3.10^{3} \mathrm{NMP} / 100 \mathrm{ml}, \mathrm{DER}=29 \%$ ) y en la cuenca baja entre
3. $10^{1}$ y $4.10^{5} \mathrm{NMP} / 100 \mathrm{ml}\left(\bar{X}=4.10^{3} \mathrm{NMP} / 100 \mathrm{ml}, \mathrm{DER}=\right.$ $19 \%$ ). Las variaciones por época (Fig. 4f) fueron: lluvia $\left(2.10^{3}-1.10^{6} \mathrm{NMP} / 100 \mathrm{ml}, \bar{X}=8.10^{3} \mathrm{NMP} / 100 \mathrm{ml}, \mathrm{DER}=\right.$ $20 \%$ ), transición $\left(3.10^{2}-2,5.10^{7} \mathrm{NMP} / 100 \mathrm{ml}, X=2.10^{4}\right.$ $\mathrm{NMP} / 100 \mathrm{ml}, \mathrm{DER}=29 \%)$ y sequía $\left(4.10^{2}-5.10^{6} \mathrm{NMP} / 100\right.$ $\mathrm{ml}, \bar{X}=4.10^{3} \mathrm{NMP} / 100 \mathrm{ml}$, DER $=22 \%$ ). Los valores promedios por cuenca fueron inferiores a $5,3 \cdot 10^{5} \mathrm{NMP} /$ $100 \mathrm{ml}$, reportada por SENIOR et al. (1999), quienes atribuyeron a la contaminación fecal dicho valor.

Existen diferencias significativas entre los contenidos de coliformes en las diferentes cuencas y épocas ( $\mathrm{PF}<$ $0,05)$, particularmente entre la presencia de coliformes en la cuenca media y las concentraciones registradas en las cuencas alta y baja. Además, fueron diferentes la cantidad de coliformes durante la época de transición y las cantidades encontradas durante la época de sequía y lluvia (transición > lluvia, sequía). Las localidades de la cuenca media con mayor presencia de coliformes fueron el río Guasdua, Cumanacoa, Arenas, Quebrada Seca, Cedeño
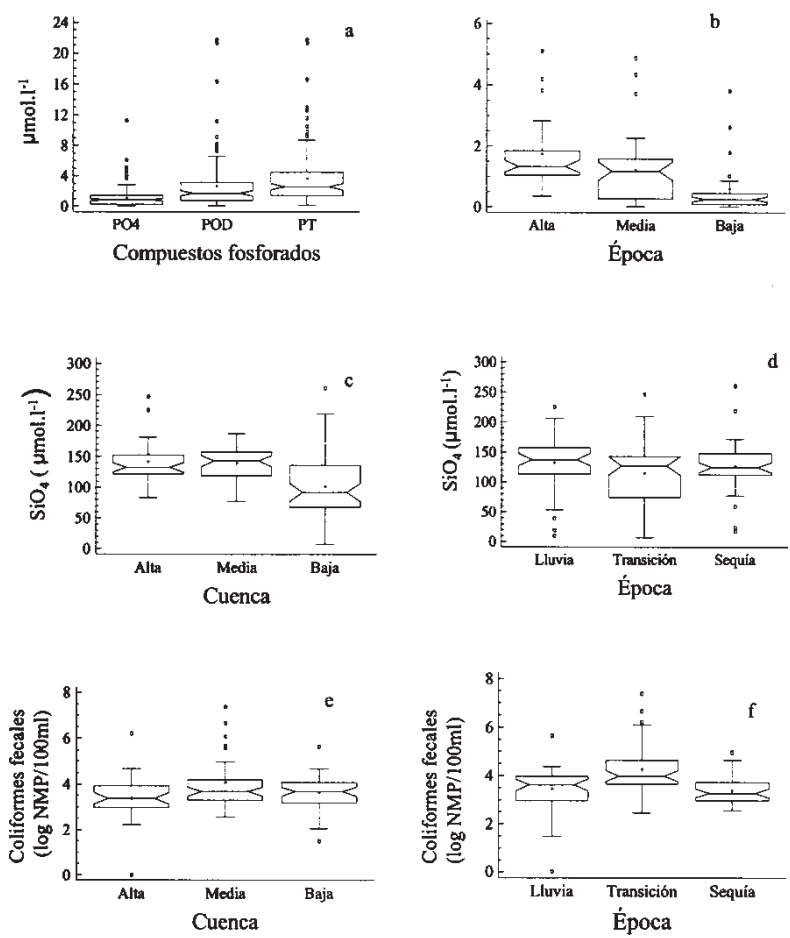

Fig. 4. Variación de los compuestos fosforados, silicatos y coliformes fecales. 
(sitios con comunidades asentadas a las orillas del río), aliviadero y desembocadura del Manzanares en la ciudad de Cumaná (cuenca baja), entre otras.

La Legislación Venezolana limita a 200 NMP/100ml de coliformes fecales en las aguas destinadas al contacto humano, por tanto las aguas del río Manzanares y de sus efluentes están contaminadas. Esta situación no es nueva, FERNÁNDEZ (1984) informó sobre niveles de coliformes entre $10^{5}$ y $10^{8} \mathrm{NMP} / 100 \mathrm{ml}$ durante el período comprendido entre 1971 y 1980, debido a los vertidos resultantes de los pobladores de los márgenes del río, desde la cuenca media hasta la cuenca baja, Godoy (1991) encontró concentraciones de $10^{4} \mathrm{NMP} / 100 \mathrm{ml}$ en la cuenca baja, mientras que SENIOR et al. (1999) hallaron concentraciones mil veces mayores en balnearios muy populares. Estos valores referenciales son inferiores a los obtenidos en esta investigación, en las mismas zonas, lo cual indica que el problema se está agravando dado el aumento demográfico en las riberas del Manzanares.

Análisis multivariado por componentes principales

La Figura 5 muestra los componentes más influyentes de la asociación y describe las variables estudiadas en función de tres componentes principales que explican el $43 \%$ de la varianza del conjunto de variables. El primer componente representa los factores que condicionan la contaminación en toda la cuenca del río (varianza explicada $=23 \%)$ y está constituido por las asociaciones positivas de este componente con la temperatura, nitritos y nitratos, amonio, fosfatos, fósforo orgánico disuelto, nitrógeno orgánico disuelto y coliformes fecales. El segundo componente, factores fisicoquímicos, representa las asociaciones positivas del $\mathrm{pH}$ y el oxígeno disuelto (varianza explicada $=20 \%$ ).

Estos resultados corroboran los planteamientos expuestos: la contaminación es causada por un conjunto de actividades agrícolas, pecuarias, industriales, recreacionales y domésticas realizadas por los pobladores de sus márgenes, cuyos residuos son vertidos directamente o son transportados en las aguas de lluvia hacia el cauce del río. Cabe resaltar que dichos desechos contienen detergentes fosforados. La abundante materia orgánica nitrogenada descartada puede elevar las concentraciones de nutrientes al ser descompuesta por los organismos heterótrofos, quienes usan el oxígeno disuelto contribuyendo al descenso del pH. Además, la abundancia de nutrientes y la temperatura cálida favorecen el

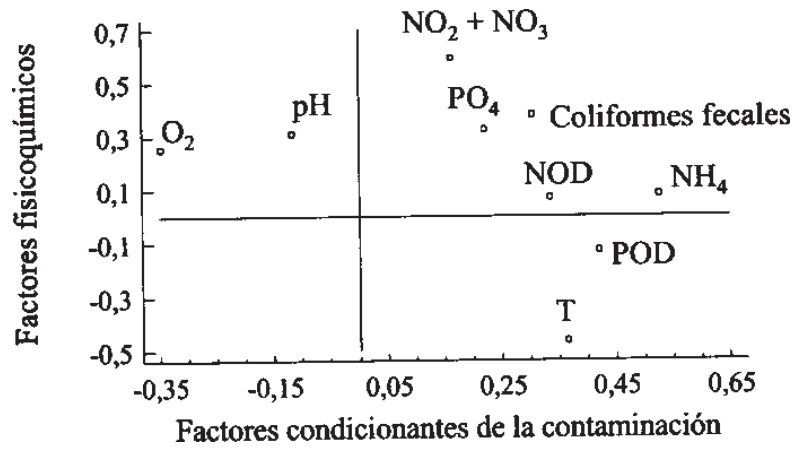

Fig. 5. Análisis multivariado por componentes principales.

crecimiento poblacional de coliformes. Los aportes afectan las condiciones ambientales del río Manzanares, su pluma y la zona costera de Cumaná, pudiendo causar daños a la biota, a su supervivencia o a sus funciones fisiológicas normales (WeIss et al. 2004).

\section{CONCLUSIONES}

Los parámetros fisicoquímicos y la presencia de coliformes fecales fueron estadísticamente diferentes en las tres cuencas y en los tres períodos, excepto el nitrito. La cuenca baja, en general, mostró las concentraciones mayores.

Los nitratos y fosfatos son las especies nitrogenadas y fosforadas inorgánicas disueltas presentes en mayor proporción.

La caída del oxígeno disuelto es mayor en la época de sequía, cuando el gasto del río disminuye.

El nivel de contaminación por coliformes fecales alerta sobre aguas no aptas para contacto humano.

Al comparar la situación actual del río con estudios previos, los resultados demuestran que ha desmejorado su calidad ambiental.

\section{REFERENCIAS}

APHA-AWWA-WPCF. 1992. Standard methods for the examination of water and wastewater. $19^{\text {th }} \mathrm{ed}$. APHA-AWWA-WPCF. Washington, USA. 410 pp. 
Alvarado, J. 2000. Distribución y comportamiento de los hidrocarburos alifáticos en aguas superficiales de la cuenca baja del río Manzanares. Trab. Grad. Lic. Química, Universidad de Oriente, Cumaná, Venezuela, 103 pp.

BENNER, R. 2004. What happens to terrestrial organic matter in the ocean? Mar. Chem. 92:307-310

Boyer, J., N. Sterling \& R. Jones. 2000. Maximizing information from a water quality monitoring network through visualization techniques. Estuar. Coast. Shelf Sci. 50:39-48.

CTI-MARN. 1999. Programa de conservación y manejo de cuencas de los ríos Carinicuao y Manzanares, Estado Sucre. Tomo I. Capítulo 1. CTI-Consultores para MARN, Cumaná, Venezuela. 30pp.

Fernández, E. 1984. Contaminación de los ríos Guasdua y Manzanares, Estado Sucre, Venezuela. Bol. Inst. Oceanogr. Venezuela. 23(1 \&2): 20 - 24

Godoy, G. 1991. Estudio espacio-temporal de los parámetros fisicoquímicos y biológicos en la zona estuarina del río Manzanares (Cumaná Venezuela). Trab. Grad. MSc. Ciencias Marinas, Universidad de Oriente, Cumaná, Venezuela, 185 pp.

GutiérRez, J. \& L. Rivero. 2000. Clasificación de las aguas superficiales del río Manzanares, tramo Cumanacoa-Cumaná. Trab. de Grad. TSU Química Aplicada, Instituto Universitario de Tecnología, Cumaná, Venezuela, 57 pp.

León, I., W. Senior \& G. Martínez. 1997. Comportamiento del hierro, cromo, cadmio y plomo total en las aguas superficiales del río Manzanares. Venezuela, durante los períodos de sequía y lluvia en el año 1994. Carib. J. Sci. 33 (1): 105-107

Márquez , A., W. Senior \& G. Martínez. 2002 a. Concentraciones y comportamiento de metales pesados en una zona estuarina de Venezuela. Interciencia. 25(6): 284-291.

, W. Senior, G. Martínez \& J. Castañeda. $2002 \mathrm{~b}$. Environmental condition of the waters of the Manzanares river, Cumaná, Sucre, Venezuela. Bol. Inst. Oceanogr. Venezuela. 41 (1 \& 2): 15-24

Martínez, G., J. Alvarado \& W. Senior. 2001. Estudio fisicoquímico de las aguas superficiales de la cuenca baja y pluma del río Manzanares. Interciencia. 26(8): 342-351

\& W. Senior. 2001. Especiación de metales pesados $(\mathrm{Cd}, \mathrm{Zn}, \mathrm{Cu}$ y $\mathrm{Cr}$ ) en el material en suspensión de la pluma del río Manzanares, Venezuela. Interciencia. 26 (2): 53-61

2005. Distribución y especiación de metales pesados en el material de suspensión de las aguas superficiales de la pluma del río Manzanares, Estado Sucre, Venezuela. Bol. Inst. Oceanogr. Venezuela. 44(2): 75-87.

Senior, W. 1994. Diagnóstico ambiental del río Manzanares. Informe Técnico. Departamento de Oceanografia, Instituto OceanográficoUniversidad de Oriente. Cumaná, Venezuela. 33pp.

.\& G. Godoy. 1990. Estudio físicoquímico del río Manzanares, Cumaná, Venezuela. Bol. Inst. Oceanogr. Venezuela. 29(1\&2):160-172

., J. Castañeda \& G. Martínez. 1999. Problemática ambiental del río Manzanares y la zona costera de Cumaná. Informe Técnico. Departamento de Oceanografia, Instituto OceanográficoUniversidad de Oriente. Cumaná, Venezuela. 27pp

Weiss, J., J. Skurnick \& P. Weiss. 2004. Studies of an contamined brackish marsh in the Hackensanck Meaddowlands of Northeaestern New Jersey: benthic communities and metal contamination. Mar. Poll. Bull.49: 1025-1035.

RECIBIDO: Octube 2008

ACEPTADO: Diciembre 2008 